Check for updates

Cite this: RSC Adv., 2019, 9, 36788

Received 24th September 2019 Accepted 4th November 2019

DOI: 10.1039/c9ra07743j

rsc.li/rsc-advances

\section{Modified melamine-formaldehyde resins improve tensile strength along with antifouling and flame retardancy in impregnation of cellulose paper $\phi$}

\author{
Xiaoyan Chen, ${ }^{a}$ Shagufta Afreen, ${ }^{\mathrm{b}}$ Xiao $\mathrm{Yu}^{\mathrm{b}}{ }^{\mathrm{C}}$ Chaohong Dong ${ }^{\star a}$ \\ and Qingshan Kong (D) *b
}

In this study, polyvinyl alcohol (PVA) and benzoguanamine (BG) modified melamine-formaldehyde (MF) resins were used to prepare two high-pressure laminates (HPLs) as well as a pure cellulose paper laminate and core sandwich laminates with the core material of aramid paper (AP) or polypropylene non-woven fabric (PPNF). The tensile strength, flame retardancy and antifouling properties of the modified MF resin laminates were studied and compared with the MF resin laminate. The tensile test results showed that the MF resins modified with BG and PVA improved the tensile strength of the impregnated paper. In comparison with pure kraft cellulose paper laminates, the aramid paper core laminates displayed comparatively higher tensile strength. Antifouling test results indicated that modified MF resin laminates had no obvious change while the MF resin laminate was stained. Thermal stability of the modified resins was investigated by thermogravimetric (TG) analysis and the results showed that the char yield of modified MF resin was higher than that of the unmodified MF resin due to the addition of BG. The modified MF resin laminates exhibited better flame retardancy properties through the analysis of limiting oxygen index (LOI), vertical burning and cone calorimetry (CONE) compared to the MF resin laminate. In addition, the flame retardancy of laminates was further enhanced when prepared with core materials of aramid paper. Scanning electron microscopy analysis of residue char after CONE tests showed that the AP-core laminate formed a dense and stable char layer compared with the loose char layer of the PPNF-core laminate. This study shows a new direction to develop sustainable highperformance flame retardant laminates for commercial decoration application.

\section{Introduction}

High-pressure laminates (HPLs), commonly available and used for decoration purposes, are prepared with paper impregnation with thermosetting resins. ${ }^{1}$ A variety of resins (epoxy resins, phenolic resins, melamine formaldehyde resins, urea resins, polyurethane prepolymers and unsaturated polyesters, etc.) can be used for impregnating kraft cellulose paper and enhancing the properties of the laminates, like dimensional stability, biological and chemical resistance, fire resistance, weathering and mechanical properties, etc., ${ }^{2}$ but melamine formaldehyde (MF) resin is the commonly-used resin to manufacture HPLs. Generally, HPL consists of three essential layers: bottom layer,

${ }^{a}$ College of Textile \& Clothing, Institute of Functional Textiles and Advanced Materials, State Key Laboratory of Bio-Fibers and Eco-Textiles, Collaborative Innovation Center of Marine Biomass Fibers Materials and Textiles of Shandong Province, Qingdao University, Qingdao 266071, China. E-mail: dongzhh@163.com

${ }^{b}$ CAS Key Laboratory of Biobased Materials, Qingdao Institute of Bioenergy and Bioprocess Technology, Chinese Academy of Sciences, Qingdao 266101, China. E-mail: kongqs@qibebt.ac.cn

$\dagger$ Electronic supplementary information (ESI) available. See DOI: 10.1039/c9ra07743j print layer and surface layer. The bottom layer is generally made from kraft cellulose paper and impregnated with phenolic resin and the print layer placed above the bottom layer which is decorative paper and impregnated by MF resin to provide color and pattern, an additional protective layer with a high-quality alpha cellulose paper is also impregnated with MF resin. ${ }^{3}$ Clearly, MF resin plays an important role in HPL manufacturing. It belongs to a class of thermoset resins, which help melamine condensation with formaldehyde under optimum conditions ( $\mathrm{pH}$, molar ratio, and temperature). ${ }^{4} \mathrm{MF}$ resin has several inherent advantages, ${ }^{5}$ namely thermal stability, flame retardancy, scratch resistance and transparency, which lead MF resin to highly applicable in adhesives, coating, paper and textile treatment. As adhesive, MF resin is extensively used particularly to impregnate paper surface overlays for plywood, particleboard and panel binders. However, some obstacles also limit their application, such as free formaldehyde, brittleness and short shelf life. ${ }^{6,7}$

In recent years, improving MF resin's properties has received increasing attention. Raval et al. ${ }^{8}$ prepared casein modified melamine-formaldehyde resins (MFC), the prepared laminates using by MFC resin had better flexibility and chemical 
resistance, although the higher content of casein led to the rate of decrease in weight loss with Rockwell hardness enhanced at higher temperature. Moreover, a study by Kim \& $\mathrm{Kim}^{9}$ reported that polyvinyl acetate (PVAc) can be incorporated with MF resin for reducing the formaldehyde emission level, resultant formaldehyde emission level decreased with increase of PVAc but the adhesion layer was broken with high temperature and pressure. Zhou et al. ${ }^{10}$ prepared modified melamine urea formaldehyde (MUF) adhesive using different generations of a hyperbranched ester-terminated-co-aldehyde-terminated poly(amidoamine)s for hydrolytic resistance, to protect particle boards degradation and improved its hydrophobicity. Zhou's study provides a new direction for finding the substitute of formaldehyde. Henriques et $a .^{1}{ }^{1}$ improved the storage stability of MF resin by using benzoguanamine (BG) as partial replacement of melamine during synthesis, the results showed that when BG was added later in the stage of reaction, the storage stability of resulting resins was improved over ten days compared to one day in unmodified MF resin. Most of physical and mechanical properties of the modified resin laminates were as good as commercial MF resin.

A study by Roşu et al. ${ }^{11}$ synthesized a series of semiinterpenetrating polymer networks (semi-IPNs) with polyhydroxyacrylate of bisphenol A (poly-HABA) and polyurethane (PU). The results showed that semi-IPNs had an improvement in the mechanical properties, the thermal stability of semi-IPNs placed between that of PU and poly-HABA resin. Semi-IPN is obtained by blending two polymers (one is line polymer where another is polymer network), it exhibits better properties than either of the polymer alone. ${ }^{\mathbf{1 2}, 13}$ PVA is one of popular linear polymer used to construct the semi-IPN, ${ }^{14}$ because it has excellent film forming ability, good mechanical stability and excellent chemical resistance along with superior biodegradability compatibility. ${ }^{15}$

In this study, we presented a facile approach to synthesize BG and PVA modified MF resins via semi-IPN network and the modified MF resin was used to fabricate HPLs. Furthermore, aramid paper (AP) and polypropylene non-woven fabric (PPNF) were also used to make core sandwich HPLs. The tensile strength, flame retardancy and antifouling properties of the fabricated laminate composites were investigated in details.

\section{Experimental}

\section{Materials}

Melamine (M), benzoguanamine (BG), polyvinyl alcohol (PVA) were purchased from Shanghai Macklin Biochemical Co., Ltd. Formaldehyde (F) 37 wt\%, sodium hydroxide $(\mathrm{NaOH})$ were purchased form Sinopharm Chemical Reagent Co., Ltd. Aramid paper (YT564-0.13 mm) was purchased from Yantai Minstad Special Paper Co., Ltd. Polypropylene non-woven fabric (610) was purchased from Dongguan Jialian Dada Non-Spinning Cloth Co., Ltd. Cellulose paper $\left(200 \mathrm{~g} \mathrm{~m}^{-2}\right)$ was prepared with chemi-mechanical pulp by Shandong Huatai Group Co., Ltd.

\section{Synthesis of resins}

The synthesis of modified MF resin was explained in Scheme S1 $(\mathrm{ESI} \dagger)$. Samples were prepared in three neck round bottom (RB)
Table 1 Composition of the M/BG/PVA composite solution produced for this study

\begin{tabular}{lllll}
\hline Sample & $\mathrm{F}(\mathrm{mol})$ & $\mathrm{PVA}^{a}(\mathrm{~mol})$ & $\mathrm{M}(\mathrm{mol})$ & $\mathrm{BG}(\mathrm{mol})$ \\
\hline MF & 2 & 0 & 1 & 0 \\
5BGMF & 2 & 0 & 0.95 & 0.05 \\
10BGMF & 2 & 0 & 0.9 & 0.1 \\
15BGMF & 2 & 0 & 0.85 & 0.15 \\
4PVA-MF & 2 & 0.04 & 1 & 0 \\
12PVA-MF & 2 & 0.12 & 1 & 0 \\
20PVA-MF & 2 & 0.2 & 1 & 0 \\
12PVA-10BGMF & 2 & 0.12 & 0.9 & 0.1 \\
${ }^{a}$ PVA was calculated by molar mass of monomer (44.05).
\end{tabular}

flask equipped with a mechanical stirrer and immersed thermometer in a thermostatic oil bath setup to maintain the temperature of flask during reaction.

Synthesis started with placing formaldehyde (F, $37 \mathrm{wt} \%$ ) and freshly prepared $10 \%$ PVA solution into the RB flask, followed by adding melamine (M) and allowed mixture to stir for $5 \mathrm{~min}$ at room temperature. Then let the temperature raised at $60{ }^{\circ} \mathrm{C}$, upheld it for 20 minutes and maintained the $\mathrm{pH}$ of mixture to 9.0 using $20 \% \mathrm{NaOH}$ solution. Furthermore, raised the temperature to $85{ }^{\circ} \mathrm{C}$ until the mixture became clear transparent solution then, let the mixture at same temperature for next 2.5 hours for proper reaction. Finally, BG was added to the transparent solution and stirred for about 15 minutes., ${ }^{\mathbf{1 , 8 , 1 0 , 1 6}}$ The addition amount of PVA and BG are listed Table 1.

Preparation of core sandwich laminates was similar to process of pure kraft laminates except core piece of kraft paper replaced by one piece of aramid paper or PP non-woven fabric (Scheme 1). All the core sandwich laminates prepared with 12PVA-10BGMF resin.

\section{Characterization}

Fourier transform infrared spectroscopy (FTIR) analysis were performed in a Nicolet 6700 FTIR spectrometer. Spectra were recorded in the wavenumber of 4000 to $500 \mathrm{~cm}^{-1}$ by signal averaging of 64 scans at a resolution of $4 \mathrm{~cm}^{-1}$. Samples were prepared by an evaporation technique approx. $5 \mathrm{~g}$ resins were poured into a PTFE crucible, and then dried in an oven at $120^{\circ} \mathrm{C}$ until the constant mass. For ${ }^{13} \mathrm{C}-\mathrm{NMR}$ analysis of resins, about $40 \mathrm{mg}$ of liquid sample were directly mixed with $0.75 \mathrm{~mL}$ DMSO-d6 and the mixture placed in an NMR tube. The high

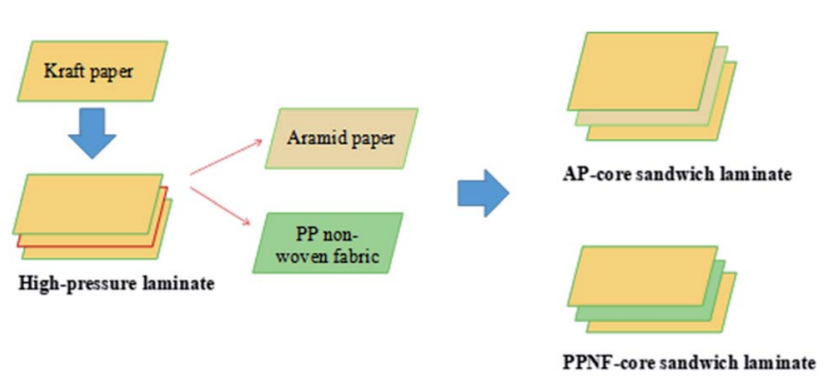

Scheme 1 The fabrication process of core sandwich laminates. 
concentration of the samples allowed very good signal/noise ratios. The spectra were obtained on a Bruker Avance III 600 NMR spectrometer using a repetition delay of $10 \mathrm{~s}$. Thermogravimetric (TG) analysis was conducted by using HTG- 1 thermal analyzer in a temperature range of $30-800{ }^{\circ} \mathrm{C}$ in static $\mathrm{N}_{2}$ atmosphere at a heating rate of $10{ }^{\circ} \mathrm{C} \mathrm{min}^{-1}$.

Tensile test was performed by microcomputer controlled electronic universal testing machine (WOW-50E1, China). The tensile strength of impregnated papers and high-pressure laminates was investigated, impregnated papers were tested with a strain rate of $1 \mathrm{~mm} \mathrm{~min}{ }^{-1}$, and laminates were tested with a strain rate of $20 \mathrm{~mm} \mathrm{~min}{ }^{-1}$.

The antifouling test performed on laminates were done accordingly to standard GB/T 17657-2013. The laminate sample was cut into a size of $10 \mathrm{~mm} \times 10 \mathrm{~mm}$ and placed in clean watch glasses, and then the surface of the sample was swabbed with ethanol. After scrubbing and drying, added a drop of coffee $\left(80^{\circ} \mathrm{C}\right)$ and ink (room temperature) to the center of the sample surface and placed it for 24 hours. Finally, the surface of the sample was swabbed with ethanol again. Observe the surface of the sample and evaluate its antifouling performance.

Limiting oxygen index (LOI) of laminates was investigated by LFY-606B digital limiting oxygen index analyzer according to standard GB/T 2046.1-2008. The dimensions of the samples were $150 \mathrm{~mm} \times 6 \mathrm{~mm} \times 1 \mathrm{~mm}$, and the values reported reflected an average from five tests. Vertical burning test was carried out by LFY-601A instrument according to standard GB/T 2408-2008. The dimensions of samples were $150 \mathrm{~mm} \times 8 \mathrm{~mm}$ $\times 1 \mathrm{~mm}$. The flammability of the samples was examined using a cone calorimeter (Fire Testing Technology) with the heat flux of $50 \mathrm{~kW} \mathrm{~m}^{-2}$ and distance between heater and sample maintained at $60 \mathrm{~mm}$. The discussed values were average, and the standard deviation calculated, curve was shown representatively in the graph.

Scanning electron microscopy (SEM, Hitachi S-4800) was conducted to investigate the surface morphology of the residue of the samples after combustion.

\section{Results and discussion}

\section{Characterization of modified MF resin}

The FTIR spectras of MF and modified MF resins was shown in Fig. 1. The broad band at $3339 \mathrm{~cm}^{-1}$, denoted the strong broad of $\mathrm{O}-\mathrm{H}$ stretching vibration and medium stretching of $\mathrm{N}-\mathrm{H}$ group. The band of $2945 \mathrm{~cm}^{-1}$ corresponded to medium C-H stretching vibration in $-\mathrm{OCH}_{2},{ }^{1}$ as well as $1166 \mathrm{~cm}^{-1}$ corresponded to $\mathrm{C}-\mathrm{O}$ stretching vibration. Moreover, the characteristic absorption of triazine ring bending vibrations of melamine occurred at $813 \mathrm{~cm}^{-1}$ and the absorption of $-\mathrm{C}=\mathrm{N}$ ring vibration was observed at $1561 \mathrm{~cm}^{-1}$. ${ }^{17,18}$

The MF resin modified by PVA and BG showed spectra very similar to the MF resin, with the same major absorption bands. In all the modified resins, new absorption bands appeared at 783 and $707 \mathrm{~cm}^{-1}$ corresponding to mono-substituted benzene, ${ }^{19}$ proving the presence of BG. We can infer from the above analysis results that the MF resin and modified resins were successfully synthesized.

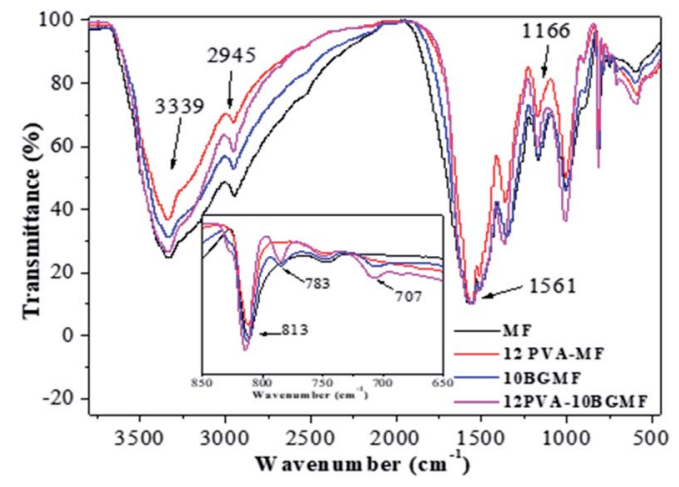

Fig. 1 FTIR spectra of MF resins and modified MF resins.
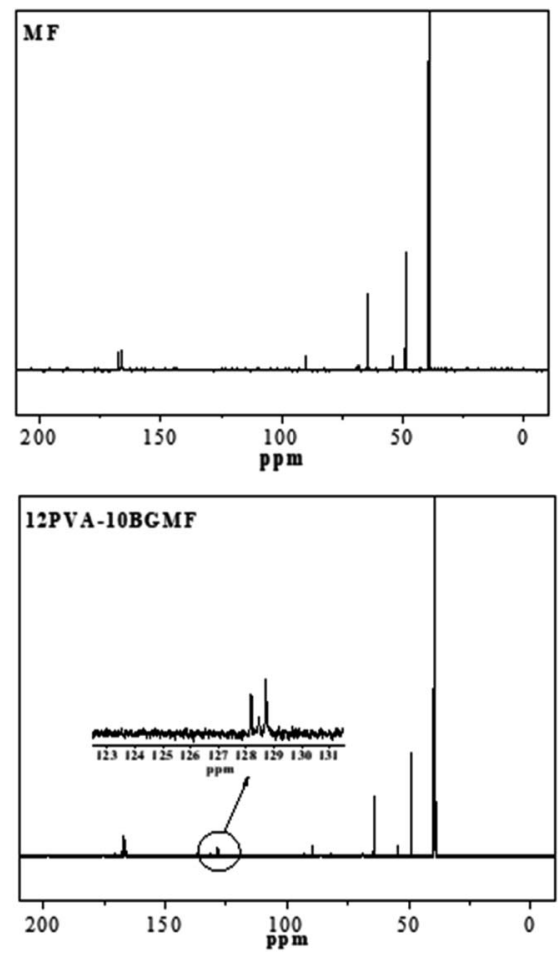

Fig. $2{ }^{13} \mathrm{C}-\mathrm{NMR}$ spectrum of MF and 12PVA-10BGM in DMSO-d6.

The structure of modified MF resin (12PVA-10BGMF resin) is also confirmed by the ${ }^{13} \mathrm{C}$-NMR spectra in Fig. 2, and interpretation of the absorption peaks showed in Table 2. The new absorption peaks observed at 128-129 ppm in modified MF resin spectra which was attributed to the phenyl carbon atoms of BG. ${ }^{20}$

\section{Thermal properties of modified MF resins}

In order to investigate the thermostability and thermal degradation process of modified MF resins and MF resin, TG and DTG analysis were carried out from $30{ }^{\circ} \mathrm{C}$ to $800{ }^{\circ} \mathrm{C}$ in $\mathrm{N}_{2}$ atmosphere. The curves of those were shown in Fig. 3.

As shown in Fig. 3a, all samples displayed decomposition at four main stages of $30-150{ }^{\circ} \mathrm{C}, 150-370{ }^{\circ} \mathrm{C}, 370-400{ }^{\circ} \mathrm{C}$ and above $400{ }^{\circ} \mathrm{C}$. Firstly, weight loss occurred at 30 to $150{ }^{\circ} \mathrm{C}$, this 
Table 2 Interpretation of the absorption peaks of MF and modified MF resins

\begin{tabular}{|c|c|c|}
\hline Chemical shift (ppm) & Structure & Name \\
\hline 167.62 & $=\stackrel{1}{\mathrm{C}} \mathrm{NH}_{2}$ & The ring carbon of triazine at primary amino groups \\
\hline 166.51 & $=\underset{\mathrm{C} N H C H_{2}}{\mid}=\stackrel{\mid}{\mathrm{C} N}\left(\mathrm{CH}_{2}\right)_{2}$ & The ring carbons of triazine at secondary and tertiary amino groups \\
\hline 89.85 & & Free formaldehyde or polyoxymethylene oligomers \\
\hline 68.44 & $\begin{array}{l}-\mathrm{NH}\left(\mathrm{CH}_{2}-\right) \mathrm{CH}_{2} \mathrm{OH} \\
-\mathrm{NHCH}_{2} \mathrm{OCH}_{2} \mathrm{NH}- \\
-\mathrm{NHCH}_{2} \mathrm{OC}_{2} \mathrm{H}_{4} \mathrm{NH}-\end{array}$ & Methylene-ether group at secondary amino groups \\
\hline 64.59 & $-\mathrm{NHCH}_{2} \mathrm{OH}$ & Monomethylol group at amino groups \\
\hline 54.45 & $-\mathrm{N}\left(\mathrm{CH}_{2}-\right) \mathrm{CH}_{2} \mathrm{NH}-$ & Methylene bridges between secondary amino groups and tertiary amino groups \\
\hline 48.89 & $\begin{array}{l}-\mathrm{NHCH}_{2} \mathrm{NH}^{-} \\
-\mathrm{NH}\left(\mathrm{CH}_{2}-\right) \mathrm{CH}_{2} \mathrm{NH}^{-}\end{array}$ & Methylene bridges between secondary amino groups \\
\hline 39.47 & & DMSO solvent peak \\
\hline
\end{tabular}
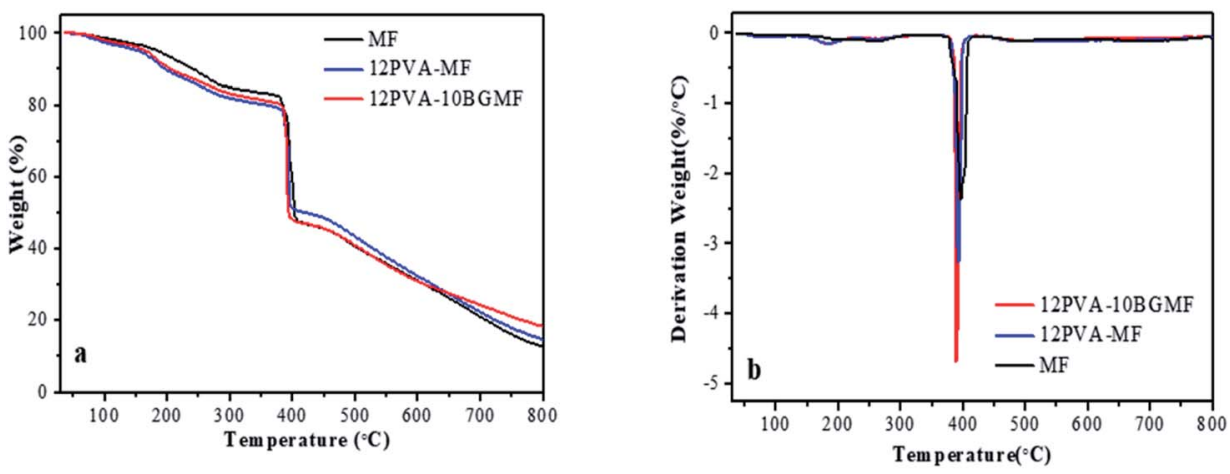

Fig. 3 (a) TG and (b) DTG curves of resins in $\mathrm{N}_{2}$.

was caused by the hydrogen bond break the evaporation of water molecule; secondly, weight loss at 150 to $370{ }^{\circ} \mathrm{C}$ was attributed to decomposition of small molecule, such as free aldehydes and oligomers; 370 to $400{ }^{\circ} \mathrm{C}$ was attributed to the breakdown of methylene bridges corresponding to a strong peak in DTG curves (Fig. 3b) at around $395{ }^{\circ} \mathrm{C}$; weight loss beyond $400{ }^{\circ} \mathrm{C}$ is attributed to the thermal degradation of the triazine ring..$^{6,21}$

The relevant parameters, including the onset decomposition temperature $\left(T_{-5 \%}\right)$, half decomposition temperature $\left(T_{-50 \%}\right)$, maximum decomposition temperature $\left(T_{\max }\right)$ and residue were summarized in Table 3. TG curve below $150{ }^{\circ} \mathrm{C}$ did not show

Table 3 TG data of the resins in $\mathrm{N}_{2}$

\begin{tabular}{lllllll}
\hline & & & & \multicolumn{2}{c}{ Residue (\%) } \\
\cline { 4 - 7 } Sample & $T_{-5 \%}\left({ }^{\circ} \mathrm{C}\right)$ & $T_{-50 \%}\left({ }^{\circ} \mathrm{C}\right)$ & $T_{\max }\left({ }^{\circ} \mathrm{C}\right)$ & $T_{\max }$ & $800{ }^{\circ} \mathrm{C}$ \\
\hline MF & 186.3 & 401.3 & 396.3 & 64.5 & 12.8 \\
12PVA-MF & 155.5 & 420.5 & 393.0 & 59.3 & 14.8 \\
12PVA-10BGMF & 166.2 & 393.7 & 388.7 & 71.5 & 18.5
\end{tabular}

significant difference for $\mathrm{MF}, 12 \mathrm{PVA}-\mathrm{MF}$ resin and 12PVA10BGMF resin. Thus, the addition of PVA and BG has no obvious effect on heat resistant property of MF resin from 30 to $150{ }^{\circ} \mathrm{C}$. The addition of PVA resulted in lower $T_{-5 \%}$ values for modified MF resin compared to pure MF resins, modified MF degraded earlier than MF resin in lower temperature because of the elimination of hydroxyl side group in PVA molecular. ${ }^{22-24}$ By contrast, $T_{\max }$ and $T_{-50 \%}$ of 12PVA-10BGMF resin declined slightly, due to the lower functionality of $\mathrm{BG}$, crosslinking density of 12PVA-10BGMF tend to be lower than MF, and the thermal stability of 12PVA-10BGMF was decreased slightly compared to pure MF resin. The final residue of 12PVA-10BGMF resin increased from $12.79 \%$ to $18.45 \%$, it showed that modified MF resins enhances the char yield at higher temperature, ${ }^{25}$ that because BG is a phenyl substituted triazine related to melamine, with the addition of BG, the phenyl count of modified MF resin was increased, so that modified MF resin exhibited better char forming characteristics. ${ }^{26}$

\section{Antifouling properties of laminates}

The antifouling properties of MF resin laminate and modified MF resin (12PVA-10BGMF resin) laminate were examined using 


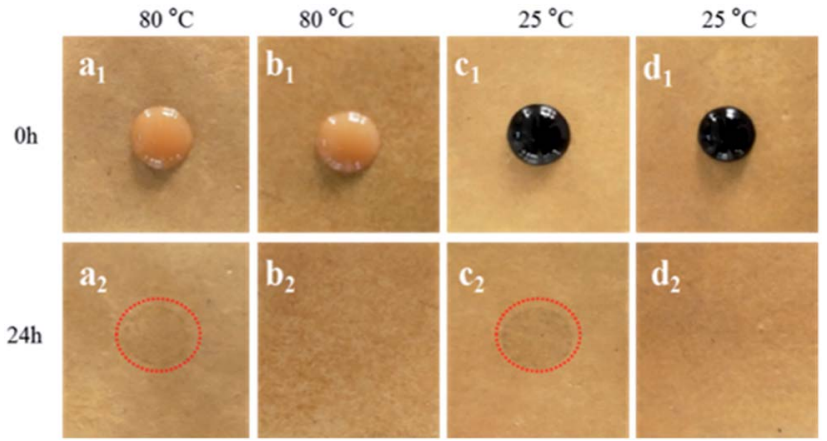

Fig. 4 Antifouling testing photographs of the laminates sample at different temp and time $\left(a_{1}\right)$ unmodified MF resin laminate began coffee stain test at $80{ }^{\circ} \mathrm{C}$; $\left(a_{2}\right)$ unmodified MF resin laminate after coffee stain at $80^{\circ} \mathrm{C}$ indicate stain on laminate; $\left(b_{2}\right)$ modified MF resin laminate began coffee stain test at $80{ }^{\circ} \mathrm{C} ;\left(b_{2}\right)$ modified MF resin laminate after coffee stain at $80^{\circ} \mathrm{C}$ indicate antifouling; $\left(\mathrm{C}_{1}\right)$ unmodified MF resin laminate began ink stain at $25^{\circ} \mathrm{C} ;\left(\mathrm{C}_{2}\right)$ unmodified MF resin laminate after ink stain at $25^{\circ} \mathrm{C}$ indicate staining; $\left(d_{1}\right)$ modified MF resin laminate of began ink stain at $25^{\circ} \mathrm{C}\left(\mathrm{d}_{2}\right)$ modified $\mathrm{MF}$ resin laminate of after ink stain at $25^{\circ} \mathrm{C}$ indicate antifouling property.

Table 4 Tensile strength of impregnated cellulose paper

\begin{tabular}{ll}
\hline Sample & Tensile strength (MPa) \\
\hline MF resin impregnated paper & 1.18 \\
4PVA-MF resin impregnated paper & 1.34 \\
12PVA-MF resin impregnated paper & 1.41 \\
20PVA-MF resin impregnated paper & 1.31 \\
5BGMF resin impregnated paper & 1.22 \\
10BGMF resin impregnated paper & 1.82 \\
15BGMF resin impregnated paper & 1.41
\end{tabular}

coffee $\left(80^{\circ} \mathrm{C}\right)$ and ink $\left(25^{\circ} \mathrm{C}\right)$ according to $\mathrm{GB} / \mathrm{T} 17657-2013$. As shown in Fig. 4, the MF resin laminate exhibited coffee stains (Fig. $4 \mathrm{a}_{2}$ ) and ink stains (Fig. $4 \mathrm{c}_{2}$ ) after the antifouling test whereas the modified resins laminate (Fig. $4 \mathrm{~b}_{2}$ and $\mathrm{d}_{2}$ ) had no obvious changes even at different temperature. It can be seen that antifouling property of modified MF resins was enhanced. These behaviours were attributed to formation of modified MF resin/PVA semi-IPN during the hot-pressing process of laminates leading to intermolecular interactions between hydroxyl groups and the increased crystallinity of MF resin and PVA. ${ }^{27}$

\section{Tensile strength property of laminates}

Tensile test was performed to evaluate the mechanical performance of the impregnated paper and laminates. Table 4 showed the relationship between tensile strength and the paper sheets impregnated by MF resin with various contents of PVA and BG. It can be seen that the addition of PVA improved tensile strength performance of the MF resin, which was as a result of the flexible chain of PVA formed physical crosslinking with the resin, then PVA shared part of the stress when subjected to external forces to improve the tensile strength of the system. Tensile strength of the impregnated paper increased by $18.64 \%$
Table 5 Tensile strength and breaking elongation of laminates

\begin{tabular}{lll}
\hline Sample & $\begin{array}{l}\text { Tensile strength } \\
(\mathrm{MPa})\end{array}$ & $\begin{array}{l}\text { Breaking elongation } \\
(\%)\end{array}$ \\
\hline Pure kraft laminate & 1.75 & 98 \\
AP-core sandwich laminate & 2.89 & 100 \\
PPNF-core sandwich laminate & 0.91 & 86
\end{tabular}

Table 6 LOI test and vertical burning test results of laminates

\begin{tabular}{lll}
\hline Sample & LOI (\%) & Vertical burning rating \\
\hline MF resin laminate & 32 & $\mathrm{~V}-1$ \\
Modified MF resin laminate $^{a}$ & 33.5 & $\mathrm{~V}-0$ \\
AP-core sandwich laminate $^{a}$ & 36.5 & $\mathrm{~V}-0$ \\
PPNF-core sandwich $^{a}$ & 34.5 & $\mathrm{~V}-0$ \\
laminate $^{a}$ & & \\
${ }^{a}$ Laminate were prepared with 12PVA-10BGMF resin.
\end{tabular}

when the content of PVA reached $12 \%$. The data showed that the substitution of BG for melamine could improve the tensile strength, and the effect was obvious. When the substitution amount of BG reached $10 \%$, the tensile strength increased by $54.24 \%$. The addition of BG reduced the crosslinking density of MF resin, contributing to reduce the stiffness and increase the tensile strength. According to the tensile strength test of impregnated paper, the paper sheets with 12\% PVA and 10\% BG added to MF resin showed better tensile strength compared with MF resin.

The modified MF resin (12PVA-10BGMF resin) prepared under optimal conditions were selected to produce pure kraft laminates and core sandwich laminates, and then the tensile strength of laminates was investigated. The resulted were shown in Table 5. Apparently, the effect of aramid paper substitution was better than polypropylene non-woven fabric, the tensile strength of AP-core sandwich laminate increased by $65 \%$ compared with pure kraft laminate; meanwhile, the breaking elongation remained constant.

\section{Flammability properties of laminates}

As fire safety of decorative material is an ongoing critical concern, research into flame retardancy of laminate is quite relevant. We investigated the flame retardancy with the use of LOI, vertical burning and cone calorimeter. LOI is used to evaluate the flammability of material and the results of all samples were showed in Table 6. LOI of all laminates were higher than the oxygen concentration of air $(21 \%)$, revealing laminates are difficult to ignite. Moreover, the LOI of the MF resins laminate was $32 \%$, and increased to $33.5 \%$ with the modified MF resin laminate, probably because modified MF resins had better ability to char formation according to the TG result of resins. Meanwhile, vertical burning rating of modified MF resin laminate achieved V-0 rating. These results indicated that flame retardancy of modified MF resin laminate was better than MF resin laminate. 
Table 7 Combustion data of cone calorimeter test

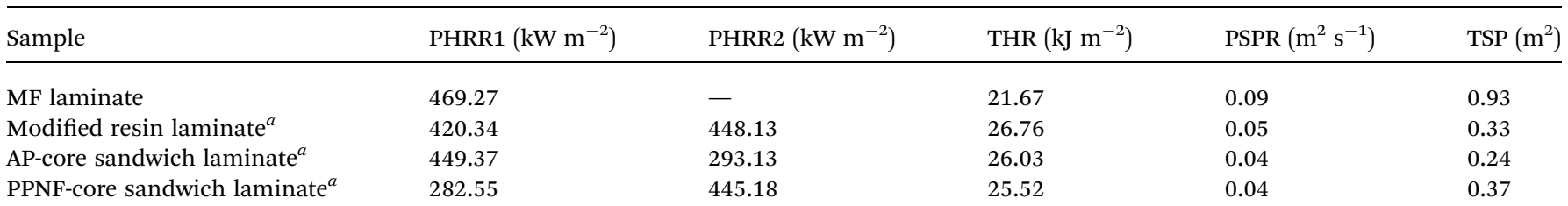

${ }^{a}$ Laminates were prepared with 12PVA-10BGMF resin.

Apparently, the core sandwich laminates exhibited higher LOI compared with the non-core sandwich laminates, it owing to aramid paper and polypropylene non-woven fabric with excellent heat resistance.

Cone calorimeter tests were performed to measure the heat and smoke releases of the laminates. ${ }^{28}$ Table 7 presented quantitative information including peak of heat release rate (PHRR), total heat release (THR), peak of smoke produce rate (PSPR) and total smoke rate (TSP). PHRR of modified MF resin laminate $\left(448.13 \mathrm{~kW} \mathrm{~m}^{-2}\right)$ showed relatively lower than MF resin $\left(469.27 \mathrm{~kW} \mathrm{~m}^{-2}\right)$, indicating that the addition of BG can promote laminate to form a protective char layer and decline heat release during combustion. ${ }^{24}$ Note that the HRR curve (Fig. 6a) of modified MF resin laminates occurred two peaks, this attributed formation of the carbon layer on the surface of laminate in the early stage of the test played the role of heat insulation and oxygen insulation, leading to the appearance of the curve trough..$^{29}$ HRR curve of AP-core sandwich laminate and PPNF-core sandwich laminate appeared obvious changes, compared with kraft paper laminate. The second peak of APcore sandwich laminate decreased evidently, and the value of the curve trough became low and duration, due to the core material-aramid paper leading to the quality of carbon improved, thermal stability enhanced. ${ }^{30}$ The first peak value of PPNF-core sandwich laminate was decreased, which indicated that PPNF core was helpful to improve the stability of laminate at the initial combustion stage. As shown in Fig. 5, modified MF resins laminate exhibited higher value than the MF resin laminate, this may be due to the addition of the PVA contributes to heat release.

The smoke from combustion is undesirable, it may increase the risk of suffocation. ${ }^{31}$ Hence, SPR is a significant parameter and can be used to evaluate the release of smoke. According to Table 7, the PSPR of modified MF resin laminate $\left(0.5 \mathrm{~m}^{2} \mathrm{~s}^{-1}\right)$ was lower than MF resin laminate $\left(0.09 \mathrm{~m}^{2} \mathrm{~s}^{-1}\right)$, modified MF resin slow the release rate of smoke efficiently. Moreover, the
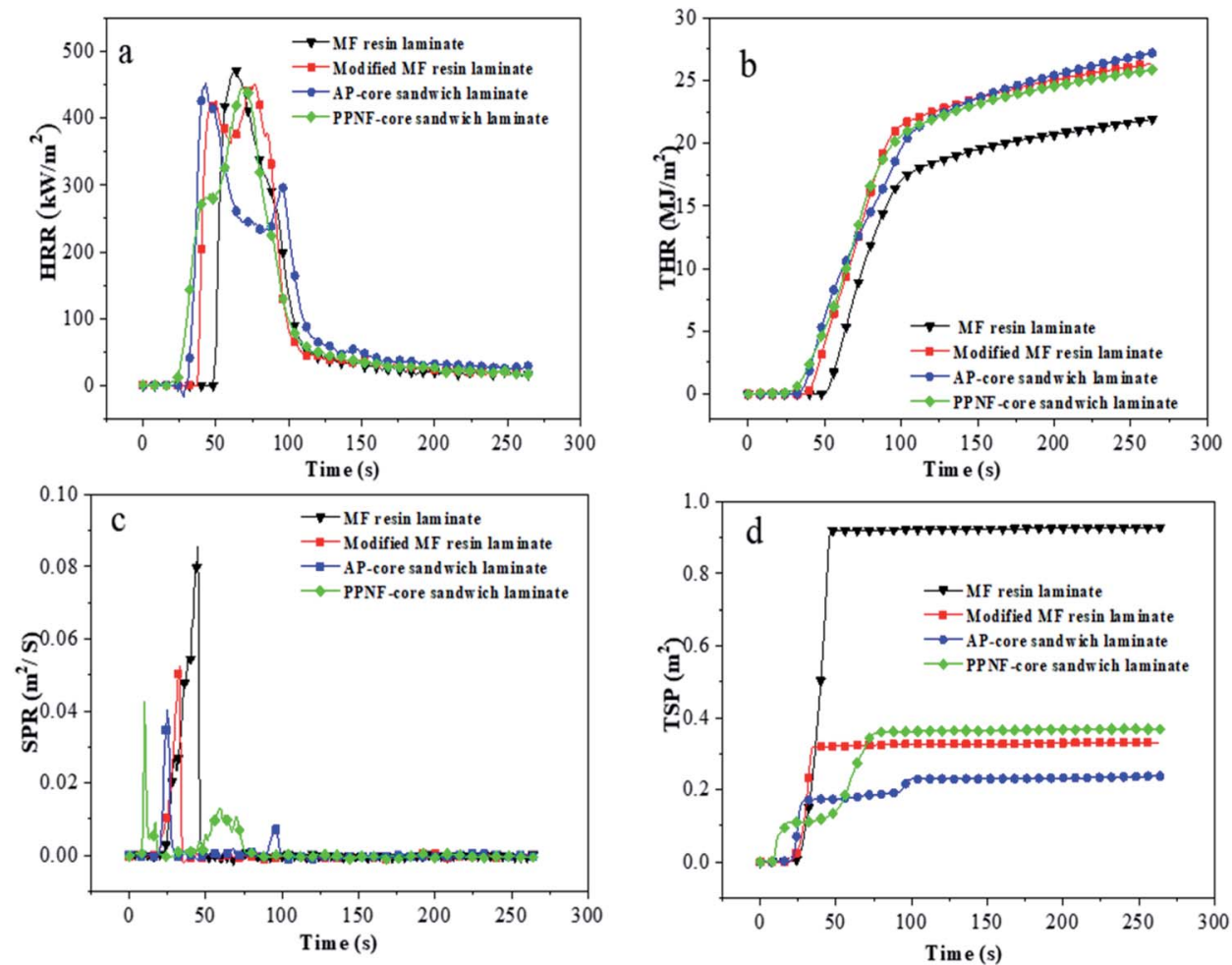

Fig. 5 Cone calorimetry data of laminates: (a) HRR curves of laminates; (b) THR curves of laminates; (c) SPR curves of laminates; (d) TSP curves of laminates. 

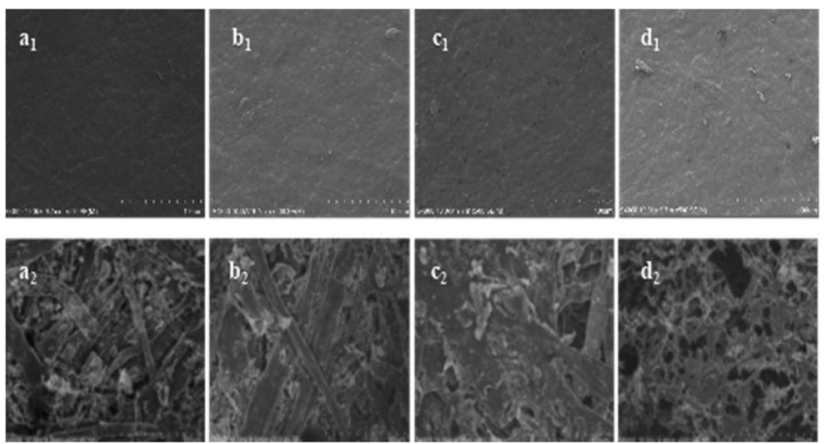

Fig. 6 SEM photographs $(\times 500)$ of microstructures of the laminates sample: $\left(a_{1}\right)$ MF resins laminate before test; $\left(b_{1}\right)$ modified MF resins laminate before test; $\left(c_{1}\right)$ AP-core sandwich laminate before test; $\left(d_{1}\right)$ PPNF-core sandwich laminate before test; $\left(\mathrm{a}_{2}\right)$ the residue of MF resins laminate; $\left(b_{2}\right)$ the residue of modified MF resins laminate; $\left(c_{2}\right)$ the residue of AP-core sandwich laminate; $\left(d_{2}\right)$ the residue of PPNF-core sandwich laminate.

SPR of AP-core sandwich laminate and PPNF-core sandwich laminate was $0.4 \mathrm{~m}^{2} \mathrm{~s}^{-1}$, this further proved that the core materials exhibit strong barrier effect to block the diffusion of the pyrolysis products. ${ }^{32}$

The data in Fig. 5 also showed that the TSP of the modified MF resin laminate was greatly reduced compared with MF resin. SPR and TSP results suggest modified MF resin suppressed the formation of smoke very well. As core material, aramid paper helped reduce the release of smoke; however, the addition of polypropylene non-woven fabric increased the formation of smoke.

\section{Surface morphology of the residues after combustion}

Surface morphology of the samples was investigated by SEM, it showed that all the laminate samples (Fig. $6 a_{1}-d_{1}$ ) have the similar surface topography before CONE test. After CONE analysis combustion, the residue of modified MF resin (12PVA10BGMF resin) laminate (Fig. 6a $\mathrm{a}_{2}$ ) kept its original structure completely while the MF resin laminate (Fig. $6 b_{2}$ ) had more fluffy and broken structure. Evidently, modified MF resin promoted carbon formation and improve the quality of carbon residue. The core sandwich laminates (prepared with 12PVA10BGMF resin) had different surface morphology compared with no-core laminates. After combustion, the surface of APcore sandwich laminate (Fig. $6 \mathrm{c}_{2}$ ) formed with continuous char layers, and the structure of the lays was compact in the high power, this structure can decrease the supply of flammable gases and reduce the exchange of heat, thereby improving the flame retardancy of laminates. ${ }^{33}$ The residue of PPNF-core sandwich laminate was showed in Fig. $6 \mathrm{~d}_{2}$, and its loose char layer as the barrier can hardly isolate the heat and oxygen from the flammable zone, ${ }^{32}$ it cannot effectively protect the laminates decomposition as the AP-core sandwich laminate.

\section{Conclusions}

PVA and BG were introduced into MF resin as modifiers successfully, and the structure of modified resins was confirmed by FTIR and ${ }^{13} \mathrm{C}-\mathrm{NMR}$. The mechanical, antifouling properties as well as the thermal, flame-retardant properties and char morphology of modified MF resins laminates were investigated. From the tensile tests, it was found that tensile strength of the laminates was increased with the incorporation of PVA and BG, and the tensile strength of sandwich laminate was further improved when aramid paper was used for core material. According to results of antifouling test, the modified MF resin laminates yielded superior antifouling property of laminates obtained when compared to MF resin laminate. The addition of BG and PVA did not change the thermal degradation behaviour of MF resin, but produced additional carbonaceous residue in higher temperature region. PHRR of modified MF resin laminate and core laminates from cone calorimeter test reduced compared with $\mathrm{MF}$ resin laminate, corresponding to the increase of LOI. TSP of modified MF resin laminates decreased to $0.33 \mathrm{~m}^{2}$ compared with that of MF laminate (0.93 $\mathrm{m}^{2}$ ). Morphology of the residue of laminates indicated that APcore sandwich laminates formed more compact char layer. In summary, the laminates prepared with modified resins had good tensile strength along with the flame retardancy and antifouling property. The study can potentially offer a new pathway to prepare the high-performance HPL with better flame retardancy by using different core materials and modified MF resin.

\section{Conflicts of interest}

There are no conflicts to declare.

\section{Acknowledgements}

This work was supported by National Key R\&D Program of China "Study on High Efficiency and Clean Pulping and Production Technology of Functionalized Products" (No. 2017YFD0601005) and Natural Science Foundation of Shandong Province (ZR2018MEM026).

\section{References}

1 A. Henriques, N. Paiva, M. Bastos, J. Martins, L. Carvalho and F. D. Magalhães, J. Appl. Polym. Sci., 2017, 134, 45185.

2 K. D. Bunkowski, US Pat., 4076896, 1978.

3 D. J. Merline, S. Vukusic and A. A. Abdala, Polym. J., 2013, 45, 413.

4 C. U. Pittman Jr, M. G. Kim, D. D. Nicholas, L. Wang, F. A. Kabir, T. P. Schultz and L. L. Ingram Jr, J. Wood Chem. Technol., 1994, 14, 577-603.

5 V. Tsvetkov and M. Y. Zueva, Polym. Sci., Ser. D, 2011, 4, 164166.

6 M. Kohlmayr, G. Zuckerstätter and A. Kandelbauer, J. Appl. Polym. Sci., 2012, 124, 4416-4423.

7 T. Li, M. Cao, B. Zhang, L. Yang and G. Du, Materials, 2018, 11, 2571.

8 D. K. Raval, A. J. Patel and B. N. Narola, Polym.-Plast. Technol. Eng., 2006, 45, 293-299.

9 S. Kim and H.-J. Kim, Int. J. Adhes. Adhes., 2005, 25, 456-461. 
10 X. Zhou, H. Essawy, A. Pizzi, J. Zhang, X. Li and G. Du, J. Polym. Res., 2014, 21, 379.

11 D. Roşu, C. Ciobanu and C. Caşcaval, Eur. Polym. J., 2001, 37, 587-595.

12 S. Rehmani, M. Ahmad, M. U. Minhas, H. Anwar and M. Sohail, Polym. Bull., 2017, 74, 737-761.

13 S. R. Kim, S. H. Yuk and M. S. Jhon, Eur. Polym. J., 1997, 33, 1009-1014.

14 R. Hodge, G. H. Edward and G. P. Simon, Polymer, 1996, 37, 1371-1376.

15 J. Wang, H. Chen, Y. Xiao, X. Yu and X. Li, Int. J. Electrochem. Sci., 2019, 14, 1817-1829.

16 H. W. Yan, J. L. Wei, B. Yin and M. B. Yang, Polym. Bull., 2015, 72, 2725-2737.

17 V. Nemanič, B. Zajec, M. Žumer, N. Figar, M. Kavšek and I. Mihelič, Appl. Energy, 2014, 114, 320-326.

18 L. Yuan, G.-Z. Liang, J.-Q. Xie and S.-B. He, Colloid Polym. Sci., 2007, 285, 781-791.

19 A. Antunes, M. Duarte, N. Paiva, J. Ferra, J. Martins, L. Carvalho, A. Barros-Timmons and F. D. Magalhães, Int. J. Adhes. Adhes., 2018, 87, 142-150.

20 I. Y. Slonim, S. Alekseyeva, B. Arshava, G. Matvelashvili, N. Romanov, N. Potseluyeva and N. Bashta, Polym. Sci. U.S.S.R., 1985, 27, 2843-2851.
21 F. Salaün and I. Vroman, Eur. Polym. J., 2008, 44, 849-860. 22 J. Zhang, E. Fleury, Y. Chen and M. A. Brook, RSC Adv., 2015, 5, 103907-103914.

23 B. Holland and J. Hay, Polymer, 2001, 42, 6775-6783.

24 Y. Lin, B. Yu, X. Jin, L. Song and Y. Hu, RSC Adv., 2016, 6, 49633-49642.

25 W. Wu, M. Li, Y. Zhong, M. Zong, S. Xiao, X. Li and F. Xie, RSC Adv., 2016, 6, 3267-3275.

26 Y. X. Wang and H. Ishida, Polymer, 1999, 40, 4563-4570.

27 N. A. Peppas, Macromol. Chem. Phys., 1977, 178, 595-601.

28 J. Liu, J. Tang, X. Wang and D. Wu, RSC Adv., 2012, 2, 57895799.

29 X. P. Hu, Y. L. Li and Y. Z. Wang, Macromol. Mater. Eng., 2004, 289, 208-212.

30 F. Xie, P. Qin, L. Zhuo, Z. Lu and Y. Wang, J. Mater. Sci.: Mater. Electron., 2018, 29, 12161-12168.

31 Q. Lv, J. Q. Huang, M. J. Chen, J. Zhao, Y. Tan, L. Chen and Y. Z. Wang, Ind. Eng. Chem. Res., 2013, 52, 9397-9404.

32 Q. Zhang, Z. Li, X. Li, L. Yu, Z. Zhang and Z. Wu, Chem. Eng. J., 2019, 356, 680-692.

33 T. Liu, L. Sun, R. Ou, Q. Fan, L. Li, C. Guo, Z. Liu and Q. Wang, Chem. Eng. J., 2019, 368, 359-368. 